\title{
Demographic Change and Representation by Population in the Canadian House of Commons
}

\author{
Don Kerr \\ Department of Sociology \\ Kings University College \\ University of Western Ontario \\ London, Ontario, Canada \\ dkerr@uwo.ca

\section{Hugh Mellon} \\ Department of Political Science \\ Kings University College \\ University of Western Ontario \\ London, Ontario, Canada
}

\begin{abstract}
This paper considers Canadian representational debates, including a brief sketch of how electoral districts are defined across geography and population. Electoral boundary commissions in Canada have long differed in terms of the relative importance to be placed on population in decisions relating to the delineation of boundaries of federal electoral districts. As argued in this paper, the traditional understandings and agreements that have shaped decisions relating to electoral districts are increasingly at odds with Canada's emerging demographic realities. In a nation that is highly reliant on immigration in maintaining its population, the current representational order arguably penalizes regions of the country which are growing most rapidly, and in particular, where new immigrants are most likely to locate. The current paper also considers possible reforms in the manner in which electoral districts are drawn, which at a minimum could involve the use of more up to date and accurate demographic data.
\end{abstract}

Key Words: Electoral representation; demographic change; electoral reform; population distribution

CSP 2010, 37.1-2: 53-75 


\section{Résumé}

Cet article examine les débats de représentation au Canada et inclus une ébauche de comment les circonscriptions électorales sont définies aux niveaux géographique et démographique. Les commissions de délimitation des circonscriptions électorales du Canada divergent depuis longtemps au sujet de l'importance placée sur la population dans les décisions reliées aux délimitations des circonscriptions électorales fédérales. Tel que maintenu dans cet article, les ententes et les accords qui ont déterminé les décisions liées aux circonscriptions électorales sont de plus en plus en désaccord avec la réalité démographique émergente. Dans un pays qui dépend fortement sur l'immigration pour maintenir sa population, on peut soutenir que le décret de représentation actuel pénalise les régions du pays qui vivent une plus forte croissance, en particulier dans les régions où les immigrants ont plus tendance à s'installer. L'article considère aussi les possibilités de réformer la manière dont les circonscriptions électorales sont tracées, ce qui au minimum pourrait requérir de s'appuyer sur des données démographiques plus à jour et plus exactes.

Mots clés : Représentation électorale, change démographique, réforme électorale, distribution démographique

\section{Introduction}

Population growth in Canada is becoming increasingly uneven. Selected regions of the country are experiencing a virtual population explosion while others are facing a near population implosion. This demographic situation is largely the by-product of current patterns of fertility, mortality and migration (both internal and international). As migration in particular tends to be highly selective, with the overwhelming majority of migrants settling in a limited number of destinations, certain regions of the country are facing major challenges in accommodating the rapid social and economic changes associated with population growth or decline. These changes have all sorts of important implications for individuals, social groups and regions, as well as for governments. For example, the increasingly uneven distribution of Canada's population has important implications for the manner in which Canadians are represented in the Canadian House of Commons.

CSP 2010, 37.1-2: 53-75 
Demographic Change and Representation by Population in the Canadian House of Commons

The current paper will consider Canadian representational debates, including a brief sketch of how electoral districts are defined across geography and population. Electoral boundary commissions in Canada have long differed in terms of the relative importance to be placed on population in decisions relating to the delineation of boundaries of federal electoral districts. As argued in the current paper, the traditional understandings and agreements that have shaped decisions relating to electoral districts are increasingly at odds with Canada's emerging demographic realities. In a nation that is highly reliant on immigration in maintaining its population, the current representational order arguably penalizes regions of the country that are growing most rapidly and where new immigrants are most likely to locate.

This paper also considers possible reforms in the manner in which electoral districts are drawn, which at a minimum could involve the use of more up to date and accurate demographic data. While Canada's most populous ridings also tend to be its fastest growing, the infrequency of boundary adjustments (typically with 10-15 years between adjustments) serves to further attenuate the relative influence of Canadians living in its fastest growing provinces, regions and cities. Secondly, as carefully documented by Statistics Canada, the Census has a problem with undercount (or persons completely missed in the enumeration), which again tends to be most problematic in Canada's fastest growing provinces and regions (Statistics Canada 2008a). Thirdly, this paper argues that with legislative amendment and revised direction, Canadian electoral commissions could improve on voter parity within provinces - by merely narrowing and enforcing a range of acceptable variation in population size across ridings. These comments are made realizing that past compromises and non-demographic concerns have traditionally played a major role in determining Canadian apportionment.

\section{Current Distribution of Seats across Provinces and Territories}

Table 1 portrays the current distribution of federal electoral districts by province and territory as introduced with the 2004 apportionment. While the present formula begins by distributing 278 seats on the basis of the 2001 Census counts alone [column 3], the existence of various clauses and protections for slower growing provinces leaves for a further allocation of 27 ridings across provinces and 3 ridings to the territories [column 4]. As a result, there is a departure from equality in the size of ridings across provinces, with specific provinces under represented and others over represented.

Both the Senate Floor rule as introduced in 1915 and a "grandfather clause" as introduced in the 1970 s serve to protect the representation of Canada's slower growing provinces (see Courtney 2001, 2008 for a detailed overview of these arrangements.) An additional wrinkle in the system is the 
assignment of one seat each for the sparsely populated territories - Yukon, Nunavut and the Northwest Territories. Briefly, this "grandfather clause" assures that a province's number of seats on the basis of population alone never falls below what it was in the $33^{\text {rd }}$ Parliament (following the 1976 redistribution), while the Senate Floor assures that a province's number of seats is never lower than its constitutionally mandated number of senators. As demonstrated here, both of these provisions are to the disadvantage of Canada's fastest growing provinces and regions..

Table 2 includes, for comparative purposes, an alternative distribution as theoretically obtained if population were the exclusive factor in the allocation of federal electoral districts. This latter distribution, rooted strictly on the basis of population, also begins with more accurate demographic data, moving beyond the use of mere census counts. While Statistics Canada has long generated highly accurate population estimates, Elections Canada continues to rely on unadjusted census counts in applying its representational formulae - despite the fact that there are non-trivial and well documented problems in the census numbers. For example, Statistics Canada estimated with a high level of precision that almost one million persons were missed in the 2001 Census, with almost half a million missed in Ontario alone [column 7]. This adjustment for census coverage error is fundamental to Statistics Canada's program of providing accurate population estimates to the Federal Government, particularly since undercount varies in important manners across provinces and territories (Statistics Canada, 2008b). The accuracy of these adjustments are very high, with very narrow confidence intervals, to such an extent that all of the provincial governments and the Federal Department of Finance currently use these figures in the allocation of Federal-Provincial transfers and in its distribution of equalization payments (for further information on these estimates, including details on the high level of precision involved, see: Statistics Canada 2008a; Department of Finance, 2008).

The difference between the 2004 apportionment and this alternative distribution based strictly on population, hints at the extent to which selected provinces are either over represented or underrepresented in the Canadian House of Commons. If we were to consider population as our exclusive criterion in the distribution, Ontario would require an additional 12 ridings to obtain parity with other provinces - which implies that its current total be increased by more than $10 \%$. Similarly, Alberta and British Columbia would have proportionally similar adjustments, with an additional 2 and 5 seats respectively. Atlantic Canada (PEI, Newfoundland and Labrador, Nova Scotia and New Brunswick), as a whole would lose a combined total of 10 ridings, for a reduction of almost one third, while Quebec, Manitoba and Saskatchewan would lose 2, 3 and 4 seats respectively. While a failure to adjust for coverage error is partially responsible for these discrepancies (with the 2001 undercount rate highest in Ontario and B.C), the special clauses and constitutional guarantees are 


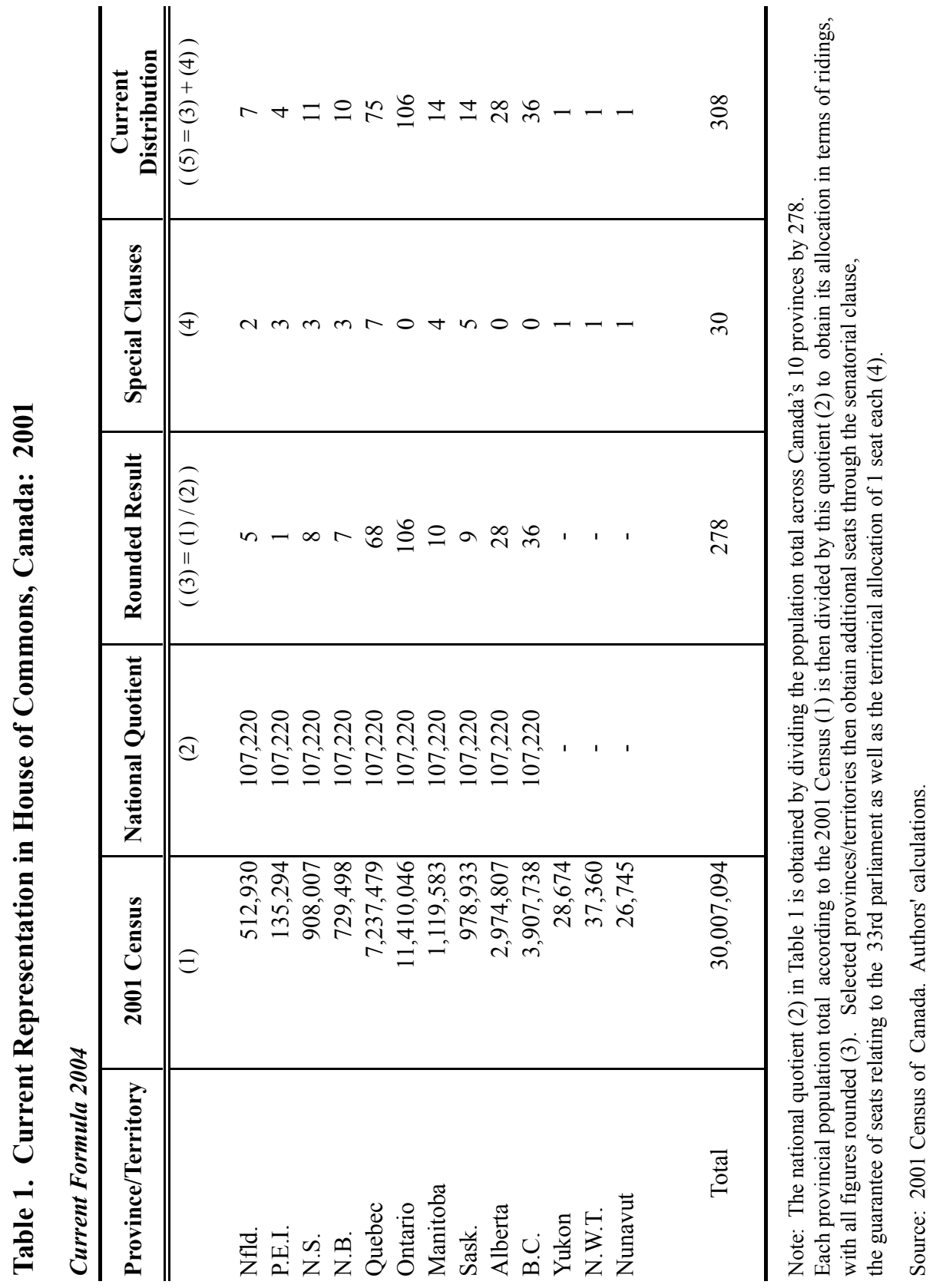

CSP 2010, 37.1-2: 53-75 


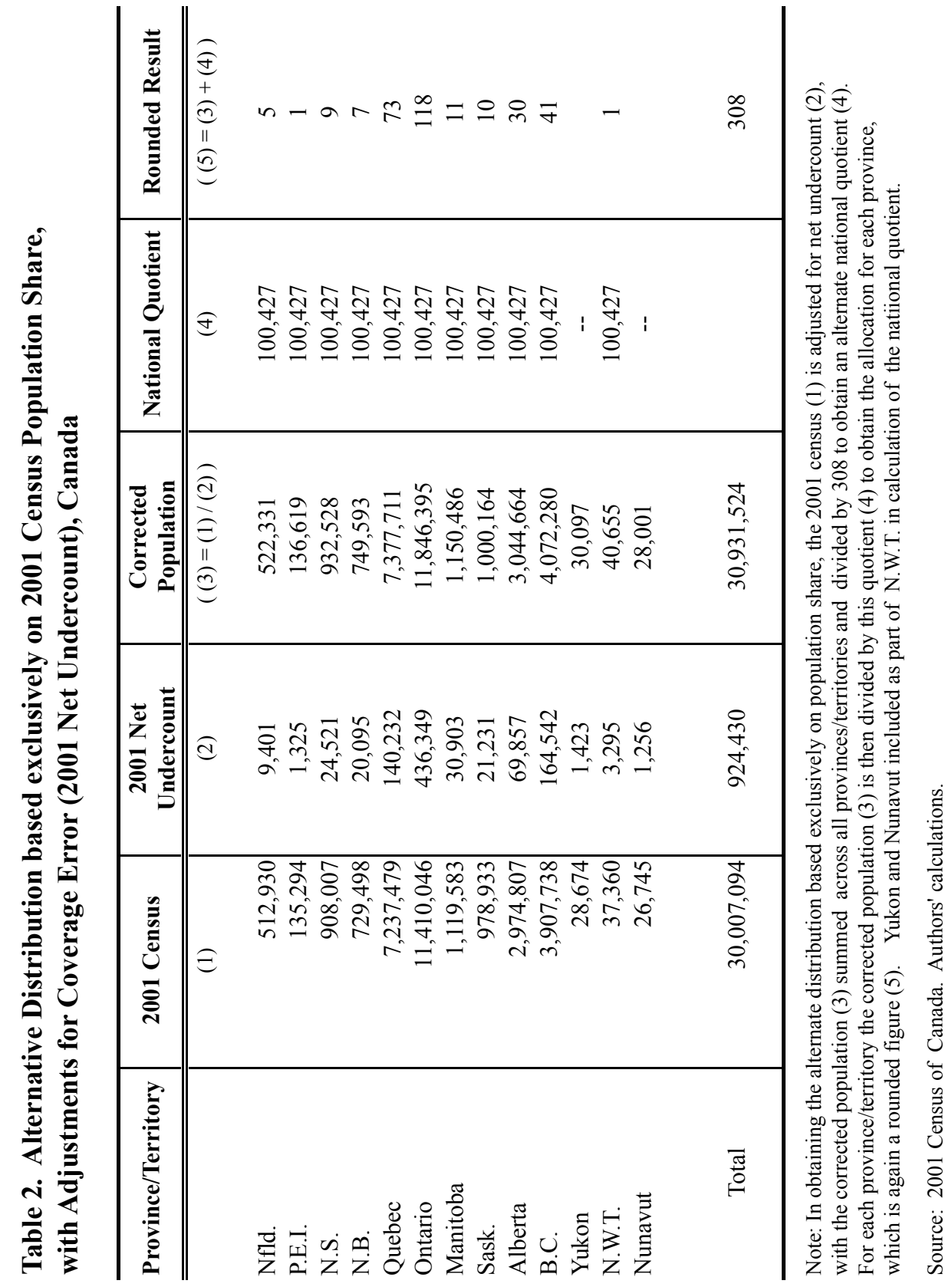

CSP 2010, 37.1-2: 53-75 
Demographic Change and Representation by Population in the Canadian House of Commons

particularly important in this context. As will be demonstrated in this paper, the current distribution is unprecedented in the extent to which Ontario, British Columbia and Alberta are underrepresented in Canada's parliament, and with current demographic trends and without reform in Canada's current representational formula, this situation will inevitably worsen into the future.

\section{The Demographic Context}

Relative to its overall population size, Canada receives a substantial share of all immigrants to North America. Currently, the admission of over 200,000 immigrants annually represents over two thirds of Canada's population growth (Statistics Canada 2008b). On an annual basis, since 1994, net international migration has comprised a larger percentage of total population growth than has natural increase (births-deaths). This situation has contributed to a sizeable share of Canada's population being foreign born -19.9 percent according to the 2006 Census (Statistics Canada 2008). The comparable figure in the United States is 11.1 percent (U.S. Census Bureau 2004) which highlights the relative importance of immigration to Canada's demographic and socio-economic development. In a context of below replacement fertility and declining rates of natural increase, this is fundamental in explaining why Canada's overall population growth and distribution is expected to become increasingly uneven as we move further into the $21^{\text {st }}$ century.

As portrayed in Figure 1, Canada's population growth has been highly uneven over the last several decades, as provinces characteristically grew either noticeably faster or noticeably slower than the national average. For the country as a whole, the population has more than doubled since 1951 (up 126\%), but all provinces except Ontario, Alberta and British Columbia had much lower rates of growth. In other words, most provinces are either markedly below or markedly above the national average of growth. This uneven population growth is directly related to the aforementioned importance of immigration to Canada's demographic growth, while to a lesser extent, internal migration has also contributed to this pattern (for a recent summary of these trends, see: Beaujot and Kerr 2004, 2007).

Population growth is expected to become increasingly uneven as Canada becomes progressively more reliant on immigration in maintaining numbers. Over the last 50 years through to the present, Alberta, British Columbia, and to a lesser extent, Ontario, have all grown particularly rapidly, while Saskatchewan, Manitoba, and all of the Atlantic provinces have lagged far behind. As all regions have witnessed a reduction in their rate of natural increase, the highly selective nature of migration has contributed to this pattern. Ontario and British Columbia have managed to attract a sizeable proportion of all newcomers to Canada, while both British Columbia and Alberta have long gained population

CSP 2010, 37.1-2: 53-75 
Figure 1. Percentage Population Increase

for Canada and Provinces: 1951 - 2006

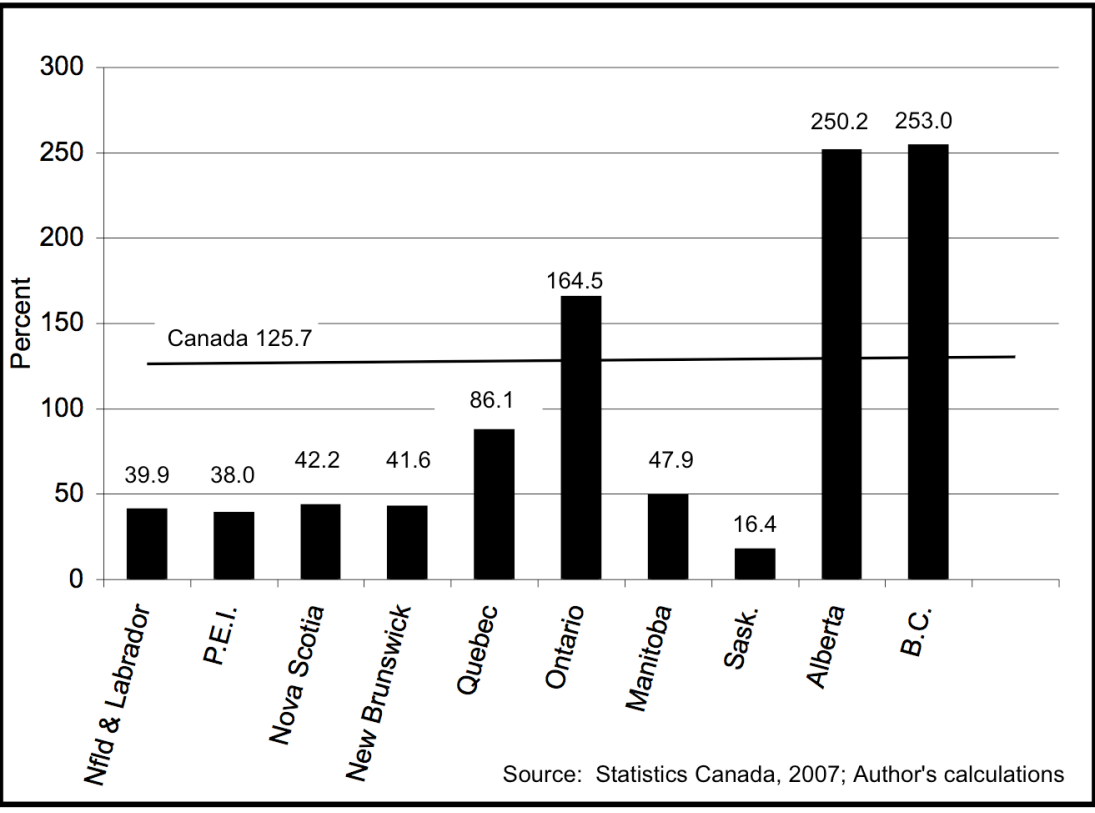

from interprovincial migration. Other provinces, including the Atlantic Provinces, Saskatchewan and Manitoba have received few immigrants and have tended to be regions of net out-migration. As a consequence, the populations of these latter provinces tend to be relatively homogeneous - with smaller proportions new to the country. Similarly, while Quebec has received a considerable number of immigrants, especially to Montreal, it has not always kept its immigrants, and has lost some of its own population with the general westward movement in North America (Dion and Coulombe 2008).

As a result of immigration, both Ontario and British Columbia have a disproportionate share of the foreign born and recent immigrant populations to this country. As reported in the 2006 Census, $38.5 \%$ of Canada's population lived in Ontario, while over one-half (54.9 percent) of Canada's foreign-born population and one-half (52.3 percent) of all recent immigrants (arriving since 2001) did so (Statistics Canada 2007). British Columbia is home to $13 \%$ of the total population, while 18.1 percent of the foreign born and about $16 \%$ of recent immigrants resided within its borders. Quebec with fully $23.8 \%$ of Canada's population reported only $13.8 \%$ of the foreign-born population with $17.5 \%$ of recent immigrants. Alberta has had a smaller share of the foreign born than total 
Demographic Change and Representation by Population in the Canadian House of Commons

population, at 8.5 percent relative to 10.4 percent. In terms of other parts of Canada, all remaining provinces and territories in combination represent 14.2 percent of Canada's population, yet include only 4.5 percent of the foreign born population and 4.8 percent of recent immigrants.

Just as population growth has been highly uneven across provinces, the same situation applies in examining the situation within provinces. Perhaps the two most predominant trends to characterize population growth and distribution within provinces over recent decades have been the continued urbanization and suburbanization of this country. For example, while only about one in two Canadians lived in urban areas roughly a half century back, the most recent census reports that over four out of five Canadians presently do so (Statistics Canada 2007). With this urbanization, the suburbs surrounding Canada's largest cities continue to lead in this growth, while most regions of the country outside of the metropolitan areas continue to lag behind. For example, over the most recent 2001-2006 period, the Golden Horseshoe region that surrounds the census metropolitan area of Toronto, following Lake Ontario from Hamilton through to Oshawa, grew by well over 600,000 people, responsible for $84 \%$ of Ontario's growth and almost $40 \%$ of the nation's as a whole. Underlying this demographic reality is immigration, as international migrants continue to overwhelmingly move into and around Canada's largest cities. Over the 20012006 period over $97 \%$ of all new migrants settling in Canada did so in its census metropolitan areas, while only negligible numbers moved to other parts of the country, i.e. to geographic regions that cover most of the county's vast and sparsely populated territory (Statistics Canada 2007).

According to the 2006 Census, $85.1 \%$ of the foreign born in Canada are citizens while the remainder are "landed immigrants" or "non-permanent residents" (i.e. persons on student or work visas, refugee claimants, etc.). The latter are obviously without the right to vote. It could be subsequently argued that this reduces the unfairness experienced by regions that are growing rapidly as a by-product of immigration. Yet it is acknowledged here that all residents in Canada are part of the civil society, whose interests could be said to be represented by elected officials, both federally and provincially. As the relationship between non-citizens and representation is a complex issue (and beyond the scope of the current paper), it could be suggested that all living and working in Canada merit some form of dedicated representation. In any course, most landed immigrants eventually do opt for citizenship in Canada, after satisfying residency requirements, i.e. most non-citizens have a long term commitment to Canada, in hope of successfully establishing themselves and their families in a new country.

As aforementioned, the "Senatorial clause" assures that a province's number of seats is never lower than its constitutionally mandated number of senators. Given the demographic changes over the last century, this has little to do with the current size of provinces and more to do with our political history

CSP 2010, 37.1-2: 53-75 
and past constitutional agreements. The "Grandfather clause" which assures that a province's number of seats never fall below the number of seats it had in the early 1980s is to the advantage of all provinces that have grown relatively slowly since. If in fact all provinces grew at roughly the same pace, these special arrangements in the distribution formula would be of little consequence. Yet the reality in Canada is that population growth is highly uneven, which in the current constitutional and legal context, places rapidly growing provinces at a distinct disadvantage in terms of representation in Ottawa. This reality of uneven growth is expected to continue well into the current century, with little to suggest that we will encounter a reversal of past trends anytime soon.

\section{Provincial Differences in the Average Population Size of Electoral Districts, Past Trends (1951-2006) and Projected (2006-2051)}

Over the latter portion of the $20^{\text {th }}$ century, Canada's population increased much more rapidly than the size of the Canadian House of Commons. For example, over the 1951-2006 period, Canada's population increased overall by 126 percent (from roughly 13.6 million to 32.6 million) while the number of seats in the House of Commons increased by only 18 percent (from 262 in 1951 to 308 in 2006). As a result, the average size of electoral districts in Canada increased from around 53,000 in 1951 to 106,000 by 2006 . This doubling in the average size of electoral districts is portrayed in Figure 2, which documents this national average over the last half century (1951-2006), as well as averages calculated for various provinces and regions. In addition, Figure 2 also includes projections on average riding size by province and nationally, well into the current century (2006-2051).

Figure 2 builds on Statistics Canada's medium growth population projection, as selected from its last round of official projection scenarios (Statistics Canada 2004). The methodology underlying these projections is the regional cohort component approach, which works with clearly specified assumptions on future fertility, mortality and migration, by province and territory. Without getting into great detail, these projections assume a continuation of demographic trends as observed over the last couple of decades. In terms of fertility, this implies stabilization at below replacement levels, while with mortality, modest gains are anticipated in extending life expectancy. In terms of migration, Ontario and British Columbia continue to receive a disproportionate share of international migrants, while Ontario, Alberta and British Columbia all receive more than their share of interprovincial migrants. In other words, these projections assume a continuation of sustained growth for Ontario, the general westward movement of population, with a continuing pattern of highly uneven population growth. While admittedly there is 
Demographic Change and Representation by Population in the Canadian House of Commons

considerable uncertainty attached to these projections, most demographers are not anticipating a significant departure or reversal of recent trends (Bourne and Rose 2007, Beach, Green and Reitz 2003). While it is obviously not possible to forecast Canada's demographic future with a high level of precision, this projection provides a reasonable forecast of Canada's future if in fact past demographic trends continue for several more decades.

Overall, Canada's population is projected to climb to about 42 million by 2051 , with international migration responsible for $100 \%$ of this growth from roughly 2030 onward. While not presented in Figure 2, this projection for Canada and its provinces with the current formula would project a House of Commons of 329 MPs by 2051. Almost all of this increase relates to the continued strong growth projected for Ontario, Alberta and British Columbia. As portrayed in Figure 2, this implies that average riding size will continue to increase, up to about 128,000 by 2051 using the current formula. If the federal government continues with the current distribution formula, population growth will be accommodated predominantly by both allowing for further growth in the size of electoral districts and to a secondary extent adding districts and increasing the size of Canada's Parliament.

Figure 2 also demonstrates how the range and variance of averages across provinces has increased with time, such that the current distribution is actually unprecedented in the extent to which Ontario, British Columbia and Alberta are underrepresented. Observing the situation in the early 1950s, the range and variance in the provincial averages were not nearly as wide as currently observed. With the aforementioned clauses protecting the representation of slower growing provinces, the range and variance in average riding size across provinces has increased - and can be anticipated to continue to increase well into the future.

\section{The Distribution of Electoral Districts within Provinces: Broad Mandates and Significant Variation}

The drawing of federal electoral boundaries within provinces is performed by independent provincial boundary commissions working under the authority of Elections Canada and the Electoral Boundaries Readjustment Act, 1970 (EBRA). These commissions operate following the release of census data, with the last apportionment in 2004 being based on the 2001 Census. Note that while Canada has had a complete quinquennial census every five years since 1956, the Electoral Boundaries Readjustment Act continues to operate as though we have only a decennial census in this country. While redistributions are scheduled to take place once every 10 years, they sometimes happen even less frequently, being delayed by elections and/or other more pressing governmental matters.

CSP 2010, 37.1-2: 53-75 


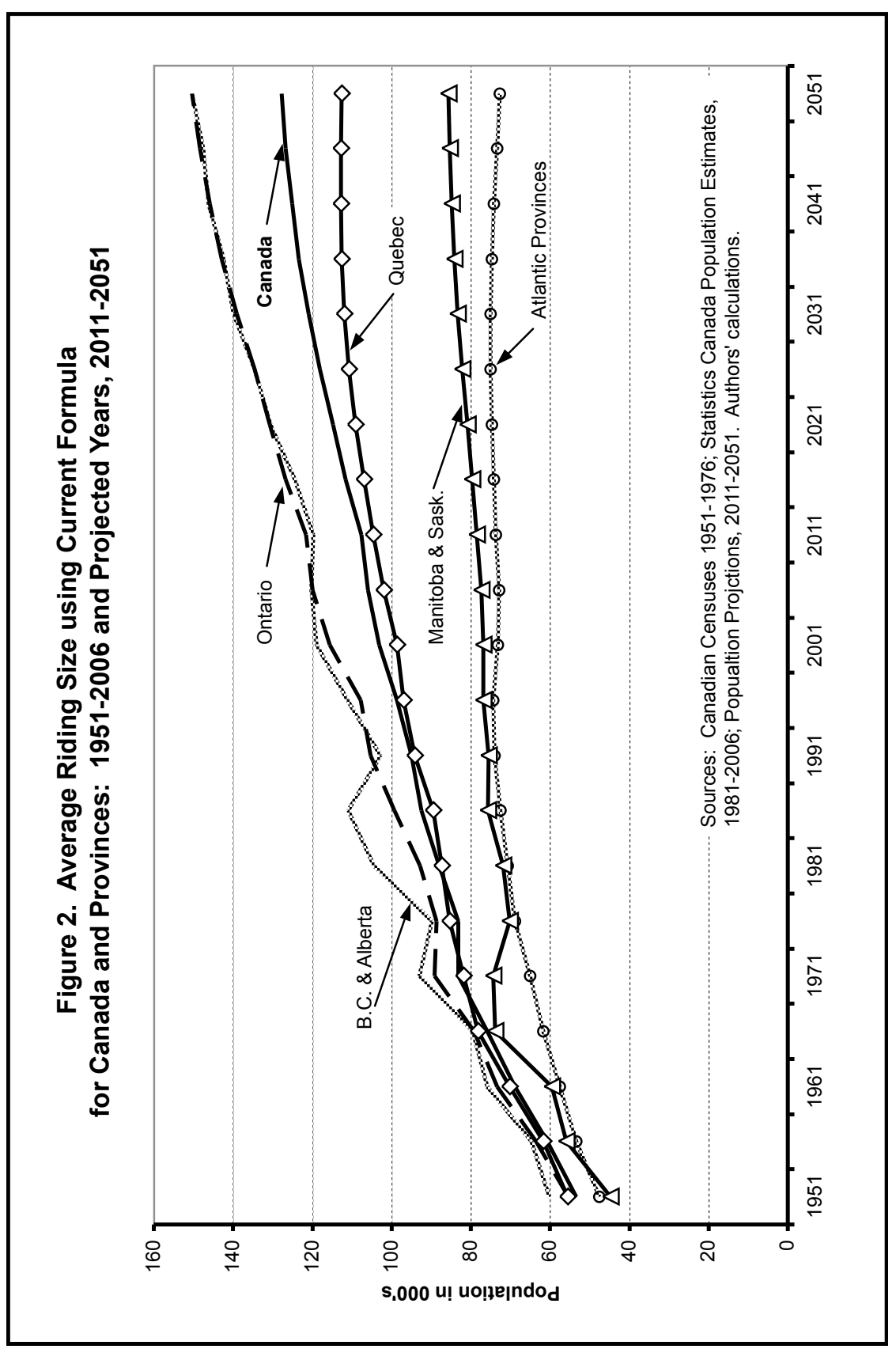

CSP 2010, 37.1-2: 53-75

64 
Demographic Change and Representation by Population in the Canadian House of Commons

As an example of this infrequency, it was not until the 2004 election that ridings based on the 1991 Census were replaced by ridings based on the 2001 census. Similarly, it was not until the 1997 election that ridings based on the 1981 Census were replaced using the 1991 census. In other words, during the latter half of the 1990s MPs in Canada were representing constituencies whose boundaries were drawn over one and a half decades earlier. Since Canada's population changed considerably over this period, the disparities in the size of ridings increased quite dramatically relative to when they were first drawn in the early 1980 s.

The history of these provincial electoral commissions, first established in the Electoral Boundaries Readjustment Act (EBRA) of 1964, is that they were a very positive step in the evolution toward non-partisan administration of elections. While the Act accords considerable discretion to boundary commissioners, Section 15(1a) of the EBRA calls for ridings within provinces to be "as close as reasonably possible" to provincial quotients. Concern over these commissions and provincial disparities relates to their rather broad mandate coupled with an indefinite commitment toward a sense of overall equality, despite Section 15(1a). This mandate is supplemented by $15(1 \mathrm{~b})$ where the commission is instructed to "consider" a range of factors including historic community of interest or identity and the geographic manageability of sparsely populated rural and northern regions. Constituency populations are then called upon to be within a range of plus or minus $25 \%$ of the provincial quotient, which is a rather wide range of acceptable variation. With such a guideline it is possible that one riding be $25 \%$ below its provincial quotient while another be $25 \%$ above. Even further, situations deemed as "extraordinary" by the provincial commissioners allow for ridings that differ in excess of this $25 \%$ guideline

Table 3 demonstrates considerable variance in the distribution of ridings by population within provinces, using the current boundaries as established in the 2004 apportionment. For each province, the provincial quotient is provided, as well the least populated and most populated electoral districts. In addition, this table includes the "percentage distribution of differences from provincial quotients", providing direct information on the extent to which specific provinces depart from voter parity. These statistics are provided alternatively with figures from the 2001 census (on which the 2004 apportionment was based), as well as with the 2006 Census and with figures projected for 2011.

Since the 2004 apportionment was based on the 2001 Census, the distribution working with this Census demonstrates the extent to which provincial commissions were willing to accept a departure from equality in riding size initially. The inclusion of information on the distribution of ridings with the 2006 Census as well as with projected figures for 2011 provides us with some evidence as to the extent to which equality in riding size declines with

CSP 2010, 37.1-2: 53-75 
demographic change and the passage of time. Very briefly, the projections in Table 2 merely assume that the demographic growth or decline as observed for specific ridings over the 2001-2006 period will continue at roughly the same pace through to 2011. As the provinces in Canada have varied widely in terms of population growth, so too have the various cities, towns, villages and rural areas within each province. As a general rule, some of the fastest growing electoral districts in Canada are in the suburban areas of the country's largest metropolitan areas.

In considering the distribution with the 2001 Census, the Boundary Commissions for all provinces except for PEI, Manitoba and Saskatchewan have allowed for ridings that fall outside of plus or minus 10 percent of the provincial quotient. With the highest level of variance, the province of New Brunswick had only 40 percent falling within this margin, as the commission favored rural and northern ridings over urban areas of the province. As a general rule, there has been a tradition of allowing for less populated electoral districts in rural areas while the most populous ridings continue to characterize urban Canada. At the other extreme, PEI managed to district all of its ridings within the 5 percent margin, just as Manitoba maintained 85.7 percent within this narrow margin.

In shifting our attention to the 2006 Census, the variation across ridings increases, as demographic change quickly serves to reduce the level of equality and voter parity. For example, while 54.4 percent of Canadian electoral districts were within plus or minus 5 percent with the initial 2001 figures, this declines to $44.6 \%$ with the 2006 figures and then only $30.5 \%$ with the 2011 projection. Similarly, while less than 1 percent of all ridings fell beyond the $25 \%$ guideline with the initial apportionment with 2001 data, by 2006 this had increased to 4.3 percent, and by 2011 we are left with more than 1 in 11 ridings ( 8.9 percent) beyond 25 percent. Similarly, a comparable percentage falls between 20-25 percent, leaving for about 1 in 6 forecasted to fall beyond plus or minus 20 percent by 2011. As the current set of boundaries are not scheduled for updating until well beyond this point in time, likely sometime in 2013 or 2014 (at the earliest), this forecasted increase in inequality is reason for concern. 
Demographic Change and Representation by Population in the Canadian House of Commons

Table 3

Distribution of Ridings by Provincial Population, Current Boundaries with 2001 and 2006 Censuses and 2011 Projections

2001 Census with Current Boundaries

\begin{tabular}{|c|c|c|c|c|c|c|c|c|c|}
\hline $\begin{array}{l}\text { Province/ } \\
\text { Territory }\end{array}$ & $\begin{array}{c}\text { Provincial } \\
\text { Quotient } \\
\end{array}$ & $\begin{array}{c}\text { Smallest } \\
\text { Riding } \\
\end{array}$ & $\begin{array}{c}\text { Largest } \\
\text { Riding } \\
\end{array}$ & $<5 \%$ & $5-10 \%$ & $10-15 \%$ & $15-20 \%$ & $20-25 \%$ & $>25 \%$ \\
\hline Nfld. & 73,276 & 27,867 & 89,743 & 28.6 & 14.3 & 28.6 & - & 14.3 & 14.3 \\
\hline P.E.I. & 33,824 & 32,245 & 35,206 & 100.0 & - & - & - & - & - \\
\hline N.S. & 82,546 & 74,445 & 88,931 & 45.5 & 54.5 & - & - & - & - \\
\hline N.B. & 72,950 & 56,464 & 83,463 & 20.0 & 20.0 & 50.0 & - & 10.0 & - \\
\hline Quebec & 96,500 & 74,475 & 105,678 & 54.7 & 37.3 & 4.0 & 2.7 & 1.3 & - \\
\hline Ontario & 107,642 & 60,572 & 122,566 & 50.0 & 29.2 & 11.3 & 3.8 & 4.7 & 0.9 \\
\hline Manitoba & 79,970 & 73,426 & 86,555 & 85.7 & 14.3 & - & - & - & - \\
\hline Sask. & 69,924 & 64,416 & 73,988 & 57.1 & 42.9 & - & - & - & - \\
\hline Alberta & 106,243 & 88,882 & 123,877 & 42.9 & 39.3 & 10.7 & 7.1 & - & - \\
\hline B.C. & 108,548 & 88,637 & 124,572 & 66.7 & 22.2 & 8.3 & 2.8 & - & - \\
\hline Total & 97,426 & 27,867 & 124,572 & 53.4 & 31.1 & 9.2 & 3.0 & 2.6 & 0.7 \\
\hline
\end{tabular}

2006 Census with Current Boundaries

\begin{tabular}{lrrrrrrrrc}
\hline \multicolumn{1}{c}{$\begin{array}{c}\text { Province/ } \\
\text { Territory }\end{array}$} & $\begin{array}{c}\text { Provincial } \\
\text { Quotient }\end{array}$ & $\begin{array}{c}\text { Smallest } \\
\text { Riding }\end{array}$ & $\begin{array}{c}\text { Largest } \\
\text { Riding }\end{array}$ & $<5 \%$ & $5-10 \%$ & $10-15 \%$ & $15-20 \%$ & $20-25 \%$ & $>25 \%$ \\
\hline \hline & & & & & & & & & \\
Nfld. & 72,210 & 26,364 & 88,002 & 28.6 & 14.3 & 14.3 & 14.3 & 14.3 & 14.3 \\
P.E.I. & 33,963 & 32,174 & 35,067 & 75.0 & 25.0 & - & - & - & - \\
N.S. & 83,042 & 71,968 & 89,448 & 36.4 & 45.5 & 18.2 & - & - & - \\
N.B. & 73,000 & 53,844 & 89,334 & 20.0 & 20.0 & 30.0 & 10.0 & 10.0 & 10.0 \\
Quebec & 100,615 & 73,140 & 122,825 & 50.7 & 28.0 & 9.3 & 8.0 & 2.7 & 1.3 \\
Ontario & 114,720 & 64,291 & 170,422 & 39.6 & 24.5 & 17.0 & 4.7 & 4.7 & 9.4 \\
Manitoba & 82,029 & 75,103 & 90,807 & 71.4 & 21.4 & 7.1 & - & - & - \\
Sask. & 69,154 & 60,551 & 76,273 & 57.1 & 28.6 & 14.3 & - & - & - \\
Alberta & 117,513 & 99,267 & 136,009 & 35.7 & 39.3 & 17.9 & 7.1 & - & - \\
B.C. & 114,264 & 86,811 & 129,241 & 47.2 & 41.7 & 2.8 & 5.6 & 2.8 & 3.3 \\
Total & 102,639 & 26,364 & 170,422 & 44.6 & 29.2 & 13.1 & 5.6 & 3.3
\end{tabular}

2011 Projections with Current Boundaries

\begin{tabular}{lrrrrrrrrr}
\hline \multicolumn{1}{c}{$\begin{array}{c}\text { Province/ } \\
\text { Territory }\end{array}$} & $\begin{array}{c}\text { Provincial } \\
\text { Quotient }\end{array}$ & $\begin{array}{c}\text { Smallest } \\
\text { Riding }\end{array}$ & $\begin{array}{c}\text { Largest } \\
\text { Riding }\end{array}$ & $<5 \%$ & $5-10 \%$ & $10-15 \%$ & $15-20 \%$ & $20-25 \%$ & $>25 \%$ \\
\hline \hline & & & & & & & & & \\
Nfld. & 71,327 & 24,940 & 95,570 & 14.3 & 28.6 & 28.6 & 0.0 & 0.0 & 28.6 \\
P.E.I. & 34,107 & 32,110 & 35,348 & 75.0 & 25.0 & 0.0 & 0.0 & 0.0 & 0.0 \\
N.S. & 83,672 & 68,873 & 96,519 & 27.3 & 36.4 & 18.2 & 18.2 & 0.0 & 0.0 \\
N.B. & 73,163 & 51,367 & 95,945 & 20.0 & 20.0 & 20.0 & 10.0 & 10.0 & 20.0 \\
Quebec & 105,122 & 71,823 & 142,723 & 40.0 & 29.3 & 10.7 & 6.7 & 8.0 & 5.3 \\
Ontario & 123,524 & 68,213 & 258,704 & 21.7 & 21.7 & 18.9 & 9.4 & 12.3 & 16.0 \\
Manitoba & 84,223 & 72,700 & 95,257 & 42.9 & 28.6 & 28.6 & 0.0 & 0.0 & 0.0 \\
Sask. & 68,526 & 56,191 & 80,004 & 35.7 & 21.4 & 14.3 & 28.6 & 0.0 & 0.0 \\
Alberta & 130,668 & 99,565 & 171,403 & 25.0 & 21.4 & 25.0 & 14.3 & 7.1 & 7.1 \\
B.C. & 120,563 & 84,940 & 150,110 & 36.1 & 30.6 & 16.7 & 5.6 & 11.1 & 0.0 \\
& & & & & & & & 8.0 \\
Total & 108,131 & 24,940 & 258,704 & 30.5 & 25.6 & 17.4 & 9.2 & 8.5 & 8.9 \\
& & & & & & & & & \\
\hline
\end{tabular}

Source: Statistics Canada, 2007; Author's calculations.

CSP 2010, 37.1-2: 53-75 


\section{Discussion}

The demographic reality of Canada has shifted, as a reliance on immigration in maintaining population growth has led to an increased concentration of new sources of diversity into urban areas - which implies that our political institutions need to adapt to these changes. As merely an example, the census metropolitan area of Toronto alone has been growing by about $2 \%$ annually over recent years, with a large proportion of this growth being driven by immigration. With its over 5 million inhabitants, over 70 percent of its population is first or second generation, i.e. either first generation immigrants or the second generation children of these immigrants (Statistics Canada 2007). Toronto has among the most populous electoral districts in the country, comparable to the very large electoral districts in cities such as Vancouver and Calgary (also growing rapidly as a by-product of international migration, supplemented by interprovincial migration). Court judgments in Canada have shown little concern with this statistical or demographic evidence, as for example, the Supreme Court of Canada has accepted the status quo with little regard of these trends (for further detail on a court challenge that made its way to the Supreme Court, see Reference re: Provincial Electoral Boundaries (Saskatchewan.) [1991] 2.S.C.R). ${ }^{1}$

\section{Potential Reform}

It is in this context, that the current paper makes several suggestions for potential reform. The first two of these recommendations are of a technical nature and relate to the under-utilization of highly accurate and up-to-date demographic information in the apportionment process. The latter two proposals are of a broader nature and could be implemented through legislative amendment. $^{2}$

Institute more frequent redistributions: As aforementioned, while Canada has a complete quinquennial census, Elections Canada continues to operate as though we have only a decennial census. Redistributions are scheduled to take place, at most, once every 10 years in Canada, and typically this occurs even less frequently. As a result, while Canada has had a census every 5 years since the 1950 s, electoral districts are typically replaced with time lags of 10-15 years. Since the cost of redistricting is very low, at mere pennies per electorate, and highly accurate census data is readily available, there is no "technical reason" why Elections Canada could not institute a more frequent apportionment. This could involve potentially the quinquennial census, which Elections Canada has up to now largely ignored. While it is appreciated that the redefinition of electoral districts can involve considerable work for local

CSP 2010, 37.1-2: 53-75 
Demographic Change and Representation by Population in the Canadian House of Commons

political parties in organizing their electoral campaigns, the current time lag seems unacceptably delayed, often due to elections and/or other more pressing governmental matters. In addition, the redistricting could at times involve a minority of ridings (i.e. only those that are growing most rapidly). As aforementioned, it was not until the 2004 election that electoral districts based on the 1991 Census were replaced by ridings based on the 2001 census (for a lag of 13 years). Similarly, it was not until the 1997 election that ridings based on the 1981 Census were replaced using the 1991 Census (i.e. with a lag of 16 years!). Redistricting, rather than being automatic in Canada, is left to the discretion of the governing party, a situation which has been far from perfect historically and a situation that need not continue.

Adjust the census data for coverage error: Statistics Canada produces on a quarterly basis highly precise population figures, based not only on the direct census counts, but also on the basis of highly precise estimates of census net undercount (see again, Table 2). Despite this fact, Elections Canada continues to work with unadjusted census counts in the distribution of seats across provinces and territories. These estimates of coverage error have been available from Statistics Canada since it first introduced its census coverage error program in the early 1970s, and are currently relied upon by many federal government departments in their day-to-day operations. For example, Finance Canada currently relies upon figures fully adjusted for coverage error in its allocation of billions of dollars in transfers and equalization payments to the provinces and territories (Department of Finance 2008).

The failure to consider census undercount is not trivial, as it is known to vary in a systematic manner across provinces and regions (for example, at only $1.0 \%$ in Quebec in 2006 relative to 3.8\% in Ontario), and is in fact known to be highest in provinces and regions that experience the greatest demographic growth through migration (Statistics Canada 2008). The reason for this is quite simple, as mobility status (moving from one address to another) is strongly associated with being missed in the Canadian Census. Again, this failure to use the most accurate data available is to the disadvantage of Canadians living in Canada's fastest growing urban ridings, as these ridings are most strongly influenced by migration from both abroad and from other parts of the country.

Reform the EBRA: The degree to which provincial commissions are permitted to deviate from population equality is defined by the EBRA. Currently set at plus or minus 25 percent, this variation across ridings within provinces from their respective provincial quotients might be considered as rather high by international standards. For example, other common thresholds used in other countries include thresholds include "virtually no deviation allowed" from a national quotient, as in the United States, to very narrow ranges as instituted in such countries as New Zealand (at only 5 percent), Australia, Italy, and the

CSP 2010, 37.1-2: 53-75 
Ukraine (at 10 percent), and Germany and the Czech Republic (at 15 percent). In addition, Section 15(2) of the EBRA allows for an even greater deviation beyond 25 percent, under what are deemed "exceptional circumstances".

It might even be possible to give more explicit legislated guidance to boundary commissions to respect the evolving ethnic and urban demographic realities in their setting of boundaries. The only barrier to narrowing this range in Canada (to perhaps 5 or 10 percent) is in fact a lack of political will in our national parliament and the loose endorsement of constituency variations found in the Supreme Court's judgment in the Saskatchewan Reference. The advantage of narrowing this range, and perhaps eliminating the "exceptional circumstances" clause as well, is that by reforming the EBRA we can introduce greater equality while also eliminating the danger or potential of further judicial review. The political justification of such a reform again relates to the current dilution of the vote of Canada's largest urban ridings.

Increase the size of the House of Commons: Political scientists have long considered the potential benefits associated with increasing the size of Canada's parliament. For example, in one of the many studies associated with the Royal Commission on Economic Union and Development Prospects for Canada - prepared over 2 decades ago - Courtney (1985) provided a careful assessment of some of the implications of a larger House of Commons. One advantage of merely adding seats to the House of Commons to address representative deficiencies and to emphasize the tight bond between constituencies and their elected legislators is that this does not require change in the Canadian Constitution, and is readily within the powers of Parliament. Furthermore, in the context of Canada's current demographic reality, this could contribute to the representation of Canada's fastest growing provinces, without depriving seats from other parts of Canada.

\section{Conclusion}

Population growth and distribution in Canada has long been highly uneven. Over the last several decades, Ontario, Alberta and British Columbia have grown particularly rapidly, while other provinces in Canada have lagged behind. Rather than being a national phenomenon, immigration and internal migration especially adds to population growth in a limited number of provinces and metropolitan areas. This uneven pattern of population growth has all sorts of important implications for individuals, social groups and regions, as well as for governments. As was demonstrated in the current paper, this situation has important implications for the manner in which Canadians are represented in the House of Commons, both currently and well into the future.

CSP 2010, 37.1-2: 53-75 
Demographic Change and Representation by Population in the Canadian House of Commons

The population size of federal electoral districts has become highly uneven, with our forecasts suggesting that this will become more of a problem into the future - in the absence of reform. In considering the variance in the average size of federal electoral districts - across provinces - the current disparities observed in Canada are unprecedented, with our projections suggesting a further widening in upcoming decades. While we have provided for inter-provincial comparisons in the current paper, we have also suggested that it is useful to move beyond an emphasis on provincial differences to also consider other important social cleavages developing as a result of demographic change. In particular, as the ridings in Canada's largest cities that have grown particularly rapidly, the relative worth of the vote in their corresponding electoral districts has declined.

The current paper argues that existing representational allocations are problematic to the extent that they are out of touch with the needs of a newly emerging Canada that has become increasingly metropolitan and ethnically and culturally diverse. Choudhry and Pal (2007), for example, point out that Canada's cultural diversity continues to be met by an electoral system that systematically undervalues the vote of new Canadians and visible minorities. In addition, selected regions of the country growing rapidly as a result of internal migration are also being penalized electorally. While there is room for potential reform in the apportionment process, including the use of more accurate and timely information, ultimately it is up to Parliament to decide on whether it wishes to enforce a narrower range in the ERBA and to increase significantly the number of ridings in select provinces. It is clear that Canadian electoral commissions, if mandated, could potentially move much further and more frequently in assuring that the distribution of ridings more closely represent the distribution of population, regardless of location. Arguments that justify the status quo are likely to be increasingly challenged by a new Canada, increasingly metropolitan and multicultural, driven by rapid population growth, demographic change and immigration.

\section{End Notes}

1. The Canadian Charter of Rights and Freedoms, and Charter 3 in particular, indicate that "every citizen of Canada has the right to vote in an election of members of the House of Commons or of a legislative assembly". Yet while nobody seems to be seriously disputing the idea that all citizens have a right to the franchise, regardless of where they live, how and whether each individual vote should be given equal weight remains in dispute. The Canadian Supreme Court in 1991 examined this issue, with lawyers debating whether or not the sizeable variance that exists in population size across electoral districts could be considered acceptable. This related to a

CSP 2010, 37.1-2: 53-75 
challenge in Saskatchewan arguing that rural ridings unacceptably deviated from the provincial quotient, which in turn was considered to be at odds with the rights as implied in Charter

Writing for the majority in this 1991 Reference, Justice (later Chief Justice) McLachlin wrote of a dichotomy, or of two different approaches which might be taken in understanding the guarantee in section 3 of the Charter of Rights and Freedoms. One view saw the Charter goal as being to "guarantee equality of voting power" while the other saw the aim being to guarantee what has been termed "effective representation". Subsequently, in elaborating upon the latter view, she indicated that "the right to vote comprises many factors, of which equality is but one" (Section B). Equal voting power would imply electoral districts of comparable, if not equal, number of people, with a close monitoring of any disparities that might surface. Yet with regard to this second view, her judgment pointed out that there is a broader range of considerations, consistent with pact practice of electoral commissions, to consider geography, constituency service, travel difficulties, and population diversity.

McLachlin and the Court ended up siding with this latter view, and thus Canadian federal constituencies continue to exhibit marked variations in population. McLachlin's dichotomy is reminiscent of a distinction drawn in Knopff and Morton's Charter Politics (1992) between "representation by population and representation by place." (348) Representation of place speaks to the recognition of established geographic communities such as provinces, towns and regions. Their longstanding existence and political needs are seen as meriting representation and where the demands of space and travel impose added difficulty representational compensation can be requested. Provincial governments have constitutional status which in turn has lead them to use their political clout to demand attention to seat allocations. This primacy upon geography and provinces in the working out of representation and apportionment has very long roots in Canada, and was very much relevant to the judgment of the Supreme Court, largely serving to preserve the status quo.

Yet in this context, we argue that there are real limits when applying such arguments to contemporary Canadian reality that involves among the highest immigration rates on this planet, an increasingly rights conscious society, and increasing urbanization and ethnic diversity. It is unclear as to how arguments emphasizing "representation by place" or "longstanding community of interest" might play out in some of the larger ridings in Vancouver or Toronto, where the overwhelming majority are either first or second generation. In other words, the Supreme Court failed to introduce a discipline that was potentially available from the Charter which could have promoted much greater equality in riding size across regions of the country. The voice of rural minorities continues to be 
Demographic Change and Representation by Population in the Canadian House of Commons

promoted to the expense of others, just as the voice of selected provinces is promoted over the voice of others.

2. The Harper government has twice in its short parliamentary life introduced measures designed to adjust the allocation of seats by province in the federal House of Commons. Bill C-56 appeared in the $1^{\text {st }}$ Session and C-22 in the $2^{\text {nd }}$ Session of the $39^{\text {th }}$ Parliament; they were parallel legislative initiatives intended for the same legislative purpose. In short, the effect of each would have been to add seats for certain provinces disadvantaged by the constitutional and political compromises which govern the allocation of provincial seats in the House. The real beneficiaries would have been the provinces of Alberta and British Columbia while Ontario would remain under-represented as a share of the House. The Bills' proposed adjustments would have the effect of adding seats for provinces not benefiting from existing constitutional and institutional protections as long as the benefiting province(s) have "a lower population than the most populous province to receive additional seats" (Barnes 2007: 6).

Briefly, Bill C-32 proposed that seats be added to the totals of all provinces with a population smaller than that of Quebec if the average population size of their electoral districts is larger than Quebec's average. Only one province, Ontario, would have a population larger than the 'most populous province receiving additional seats, Quebec; yielding it no additional seats as in the Alberta and $\mathrm{BC}$ cases. No explicit rationale was offered for this exclusion which has lead to complaint and suppositions. Without justification, the under presentation of Ontario was not equitably addressed with this legislation given that it is the only province larger than Quebec in terms of population. This led to rhetorical skirmishing between the Ontario Liberal Government and the Federal Conservative government. There was a feeling among many Liberals that the federal Conservatives were uninterested in adding seats where the electoral outcome would not likely have been to their advantage. Current priorities of the federal government have shifted elsewhere.

\section{Acknowledgement}

The authors would like to thank Stanislav Rajic for his technical assistance in the preparation of this manuscript. Responsibility for any errors rests with the authors.

CSP 2010, 37.1-2: 53-75 


\section{References}

Barnes, A. 2007. Bill C-22: An Act to Amend the Constitution Act, 1867 Legislative Summary. Ottawa: Library of Parliament.

Beach, C., A. Green and J. Reitz (eds.) 2003. Canadian Immigration Policy for the $21^{\text {st }}$ Century. Montreal: McGill Queen's University Press.

Beaujot, R. and D. Kerr. 2004. Population Change in Canada. Toronto: Oxford University Press.

Beaujot, R. and D. Kerr (eds.) 2007. Changing Faces of Canada. Toronto: Canadian Scholars' Press.

Bourne, L. S. and D. Rose. 2007. "The Changing Face of Canada: The Uneven Geographies of Population and Social Change," in Changing Face of Canada. R. Beaujot and D. Kerr (eds.), Toronto: Canadian Scholars' Press. Pp. 255-268.

Choudhry, S. and M. Pal. 2007. "Is every ballot equal? Visible vote dilution in Canada," IRPP Choices. 13: 1.

Courtney, J. 1985. "The size of Canada's parliament: An assessment of the implications of a larger House of Commons," in Institutional Reforms for Representative Government volume 38 of the Studies prepared for the Royal Commission on the Economic Union and Development Prospects for Canada. P. Aucoin (ed.), Toronto: University of Toronto Press.

Courtney, J. 2001. Commissioned Ridings: Designing Canada's Electoral Districts. Montreal: McGill-Queen's University Press.

Courtney, J. 2008. "From Gerrymanders to Independence: District Boundary Readjustments in Canada," in Redistricting in Comparative Perspective. L. Handley and B. Grofman (eds.), Oxford: Oxford University Press.

Department of Finance (Canada) 2008. Federal Transfers to the Provinces and Territories.

Dion, Patrice and Simon Coulombe 2008. "Portrait of the mobility of Canadians in 2006: Trajectories and characteristics of migrants." Report on the Demographic Situation in Canada. Statistics Canada, Catalogue 91-209X.

CSP 2010, 37.1-2: 53-75 
Demographic Change and Representation by Population in the Canadian House of Commons

Elections Canada. 2003. 2003 Representation Order.

Knoff, R. and F. L. Morton. 1992. Charter Politics. Scarborough, Ontario: Nelson Canada.

Statistics Canada. 2007. Immigration in Canada: A Portrait of the Foreign-Born Population; 2006 Census: Findings. Ottawa: Statistics Canada.

Statistics Canada. 2008a. Final Estimate of 2006 Census Coverage. Ottawa: Statistics Canada.

Statistics Canada. 2008b. Annual Demographic Estimates. Ottawa: Statistics Canada.

U.S. Census Bureau. 2004. The Foreign Born Population in the United States; Report Reference No. P20-551. Washington, D.C.: U.S. Census Bureau. 